\title{
Flow Arrest for Complex Intracranial Aneurysm Surgery by Using Adenosine
}

\author{
Xiangdong Wang, Yasuhiro Yamada, \\ Tsukasa Kawase, and Yoko Kato
}

\subsection{Introduction}

The term complex intracranial aneurysms (CIAs) refers to aneurysm at a narrow and difficult location, difficult shape, and also giant size (aneurysm that is bigger than $25 \mathrm{~mm}$ in diameter) [1]. Giant aneurysms are more likely to bleed and present as subarachnoid hemorrhage, or sometimes they become partly thrombosed with ischemic brain causing mass effect with progressive symptoms or even death. Microsurgery and clip ligation can be challenging in CIAs because it is very difficult to have a panoramic view of the aneurysm, where sometimes the parent vessel is laid beneath the aneurysm, difficult to identify all branches and perforators, and also the surgical corridor could be very deep and narrow and surrounded by important neurovascular structures. During the clipping, it is important to make sure the aneurysm is well clipped to prevent injury from any perforator (Figs. 27.1, 27.2, and 27.3). Flow arrest can be induced by using adenosine; it will briefly reduce cerebral perfusion pressure

\footnotetext{
X. Wang · Y. Yamada · T. Kawase

Department of Neurosurgery, Fujita Health University, Banbuntane Hotokukai Hospital, Nagoya city, Aichi, Japan

e-mail: kawasemi@hm8.aitai.ne.jp

\section{Y. Kato $(\bowtie)$}

Department of Neurosurgery, Fujita Health University, Toyoake, Aichi, Japan

e-mail: kyoko@fujita-hu.ac.jp
}

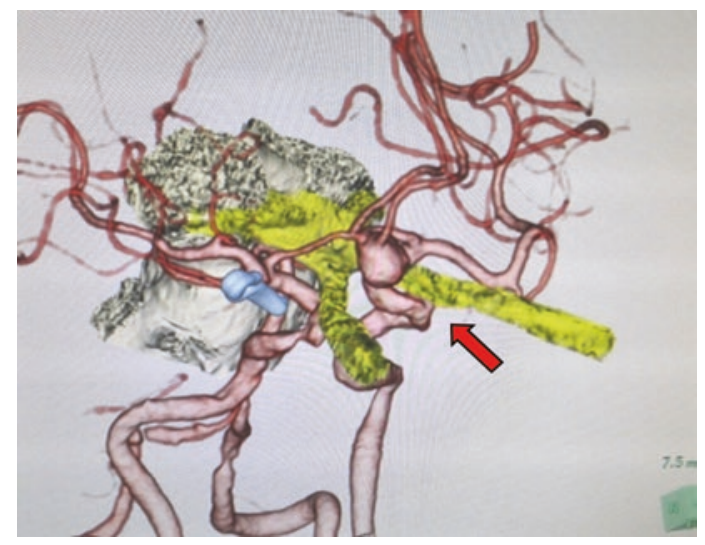

Fig. 27.1 Preoperative fusion images of CIAs

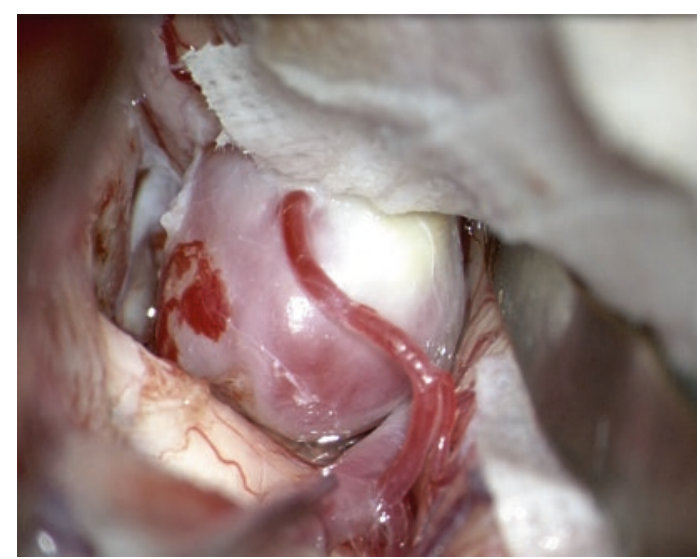

Fig. 27.2 Schematic representation of an A Com A aneurysm. The large mass does not allow circumferential dissection and visualization of the whole aneurysm, its branches, and perforators 


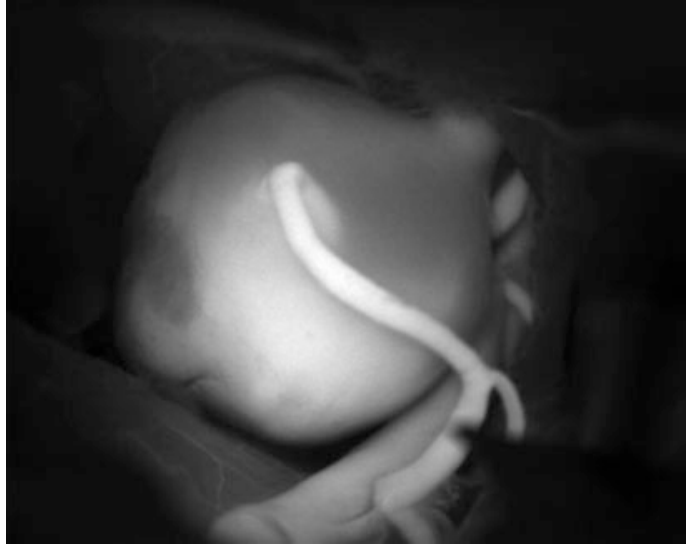

Fig. 27.3 Microsurgery-integrated indocyanine green video angiography (mICG-VA)

and the tension on aneurysm, thereby facilitating the clip ligation. The lenght of time while the flow arrest will provide the surgeon to work at the aneurysm and the parts surrounding it or even reduce the bleed if it was ruptured during dissection. It will provide the time interval for the surgeon to be able to secure the neck of the aneurysm. The adenosine is working by inducing the transient asystole for a few minutes.

There are 231 cases of intracranial aneurysms which used adenosine-induced flow arrest during microsurgery and clip ligation from 1999 to 2016 (Bebawy JF et al. have three published papers; there are some repeated cases in these three papers) [2].

\subsection{Adenosine-Induced Transient Asystole}

The adenosine is a nucleoside analog that can reduce the heartbeat and lengthen the electric conduction at the atrioventricular node. Adenosine will bind A1 receptors in the myocard, reducing adenylate cyclase activity and reducing intracellular cyclic adenosine monophosphate (c-AMP). This will prevent calcium conductance and then shut down pacemaker activity. Adenosine has a half-life of 0.6-10 s, and it is quickly washed out from the circulation by uptake into erythrocytes and vascular endothelial cells. Following the bolus injection, the heart rate will decrease linearly with the amount of dose until total AV node block happened. The adenosine effect will be seen 10-20 s after the bolus injection. There is a linear relationship between the dose and the length of asystole, and it reaches a plateau between 40 and $60 \mathrm{~s}$ at $1 \mathrm{mg} /$ $\mathrm{kg}$ body weight [3]. Going through the asystole, there will be a hypotension that may stay for up to $1 \mathrm{~min}$. In practice, the adenosine is commonly used by the emergency physician or cardiologist to treat supraventricular tachycardia [4]. In the endovascular surgery, adenosine sometimes is used during endovascular aortic aneurysm repair $[5,6]$ and AVM embolization [7, 8].

\subsection{Indications of Using Adenosine-Induced Flow Arrest for Complex Aneurysm}

There are three earlier single-patient case reports during 1999-2007. The first case was reported by Groff et al. [9]; the clipping of basilar apex aneurysm was done successfully with three doses of adenosine and no complications. Nussbaum et al. [10] then reported the second case. Nussbaum and his team successfully managed the intraoperative rupture of an A Com A (anterior communicating artery) aneurysm by using adenosine bolus injection. Prior to this attempt, they have tried temporary proximal control and cottonoid tamponade, but they failed to achieve adequate hemostasis. In this case, the adenosine facilitates the successful clipping of the aneurysm. The patient recovered very well, with no deficits and no complications related to the use of adenosine. Heppner et al. [11] reported the third case; it is a giant basilar apex aneurysm. Proximal control at the basilar trunk failed to relax the dome to allow perforator visualization and clip placement. They finally decided to give three boluses of adenosine while performing the aneurysm clipping. Sadly, this case resulted in a poor outcome, but it was considered not related with the adenosine. 
Recently, there are ten serial cases describing adenosine role in facilitating intracranial aneurysm clipping during 2010-2016.

For CIAs clip ligation, if the aneurysm size is giant, the surgeon often finds it difficult to apply proximal control such as the case with big aneurysm at ICA bifurcation when it turns to ACA and MCA [12, 13]. Many surgeons used to prepare the extracranial carotid vessel at the neck for proximal control to reduce the dome tension while clipping the aneurysm or manage the bleed if the premature rupture occurs. Nowadays, they also can combine by using balloon occlusion endovascularly and suction decompression or do the deep hypothermic circulatory arrest, but it only could be done at the hospital with complete facility $[14,15]$. Such combination of surgery may be associated with high morbidity rate that contributed from the dissection of friable arteries or distal arterial embolic occlusion due to endovascular manipulation. The other method is using cardiopulmonary bypass to facilitate clipping of difficult aneurysm, but there are risks of complication related to the bypass procedure such as arterial injury at the puncture site, emboli, and coagulopathy causing high number of postoperative intracranial hematomas [16]. If the proximal control is unfeasible for the case, then the use of adenosine may induce a short-time deep systemic hypotension with flow arrest to the parent artery $[9,11,17]$. The studies have shown that $57(24.7 \%)$ of 231 patients got adenosine during posterior circulation clipping, which include $25(10.8 \%$ ) basilar artery aneurysm and 29(12.55\%) unsorted posterior circulation aneurysm. This supports the fact that the surgeries in this area are generally more difficult, with deep and narrow corridor; thus they are technically more challenging [3, $9,11,18,19]$.

Some studies $[3,9,11,19,20]$ have pointed out that proximal control by using temporary clip remains the gold standard. The use of adenosine should be an adjunct and optional, while it's necessary during the surgery, it should not be a replacement of the temporary clip occlusion.

\subsection{Adenosine-Induced Flow Arrest}

Since the first successful use of adenosine to facilitate the clipping of difficult unruptured basilar apex aneurysm by Groff et al. [9], it has gained its popularity among neurosurgeons who were trying to do the complex aneurysm surgery.

Early surgery after the aneurysm rupture may have a higher incidence of premature rupture prior to clipping, and the surgical field sometimes so dirty by the subarachnoid blood causes difficulty to get the proximal and distal of the parent vessel. When the premature rupture happened, it is useful if the surgeon can get the blood to stop briefly and work fast to dissect the parent artery for the proximal control. The adenosine may provide long enough time to allow definitive clipping or readjust the clip position on the rupture site or trapping aneurysm with temporary clips.

\subsection{Patient Selection}

Adenosine is contraindicated for the patient with severe $(>80 \%)$ left main coronary artery stenosis, severe multivessel disease (three vessels or grafts with $>80 \%$ stenosis), AV block (sick sinus syndrome), or who is using pacemakers. It is also contraindicated to severe asthma, symptomatic asthma, and active perioperative wheezing due to the risk of bronchoconstriction.

Patient have to be carefully examined prior to surgery, including screen for cardiac function and coronary artery disease, cardiac valve, any irregular heartbeat, and cardiac conduction abnormalities.

\subsection{Dose of Adenosine}

There is no consensus yet about the optimal dose of adenosine during surgery. Luostarien et al. reported their first 16 patients with adenosine and demonstrated its safety and efficacy during surgery for ruptured intracranial aneurysm [21]. Of these 16 patients, 12 patients got 1 bolus, and 4 
patients received multiple bolus. Median dose for a single injection was $12 \mathrm{mg}(6-18)$, and the median total dose for multiple injections was $27 \mathrm{mg}$ (18-89). Ten minutes after adenosine administration, all patients were hemodynamically stable, and 13 required vasoactive drugs during the procedure.

In terms of the dose, because individual responses to adenosine vary, different patients may need different doses of adenosine [21]. We recommend we should establish an individual dose-response relationship for each patient by injecting escalating doses of adenosine.

\subsubsection{Advantages of Adenosine- Induced Transient Asystole}

1. When the blood flow stops temporarily to the parent artery, it helps in reducing tension in aneurysm and facilitating aneurysm dissection, minimizes premature rupture risk, and provides safe clip placement.

2. Adenosine has a short half-life and the circulation will be back to normal.

3. Adenosine can be given repeatedly after the patient recovers from the first dose.

\subsection{Potential Risks: Complications of Adenosine- Induced Transient Asystole}

There is $2.6 \%$ incidence of transient irregular heartbeat during recovery period [2]. One of them required intraoperative amiodarone injection to convert to sinus rhythm [3]. Troponin 1 elevation has been reported with an incidence of $1.73 \%$ [3, 19]; all of them are clinically asymptomatic in the postoperative care unit.

The adenosine is quickly metabolized and excreted from the body, but multiple bolus injection has been associated with a prolonged hypotension; it was reported that the multiple injection is used to control the premature aneurysm rupture [2]. The general agreement is to wait for complete hemodynamic return to get back to normal before giving another bolus injection.

\subsection{Expert Opinion}

There is still no general consensus about adenosine dose and how fast it should be given in every bolus injection. It is best to always prepare all necessary checks for the patient that is going to have complex aneurysm surgery. It includes the coronary vessel, heart conductivity study, its valve, and other comorbid condition such as asthma. It is very important if the surgeon is going to use the adenosine if other efforts for proximal control fail. Authors recommend that adenosine should be available all the time in the operating room and it should be used judiciously if the proximal control fails, is unsafe, or is difficult.

\section{References}

1. Hanel RA, Spetzler RF. Surgical treatment of complex intracranial aneurysms. Neurosurgery. 2008;62(6 Suppl 3):1289-97.

2. Guinn NR, McDonagh DL, Borel CO, et al. Adenosine-induced transient asystole for intracranial aneurysm surgery: a retrospective review. J Neurosurg Anesthesiol. 2011;23(1):35-40.

3. Bebawy JF, Gupta DK, Bendok BR, Hemmer LB, et al. Adenosine-induced flow arrest to facilitate intracranial aneurysm clip ligation: dose-response data and safety profile. Anesth Analg. 2010;110(5):1406-11.

4. Parker RB, McCollam PL. Adenosine in the episodic treatment of paroxysmal supraventricular tachycardia. Clin Pharm. 1990;9(4):261-71.

5. Kahn RA, Moskowitz DM, Marin ML, et al. Safety and efficacy of high-dose adenosine-induced asystole during endovascular AAA repair. J Endovasc Ther. 2000;7(4):292-6.

6. Plaschke K, Boeckler D, Schumacher H, Martin E, Bardenheuer HJ. Adenosineinduced cardiac arrest and EEG changes in patients with thoracic aorta endovascular repair. Br J Anaesth. 2006;96(3):310-6.

7. Hashimoto T, YoungWL ABD, Joshi S, Ostapkovich ND, Pile-Spellman J. Adenosine-induced ventricular asystole to induce transient profound systemic hypotension in patients undergoing endovascular therapy: dose-response characteristics. Anesthesiology. 2000;93(4):998-1001.

8. Pile-Spellman J, Young WL, Joshi S, et al. Adenosineinduced cardiac pause for endovascular arteriovenous malformations: technical case report. Neurosurgery. 1999;44(4):881-6.

9. Groff MW, Adams DC, Kahn RA, Kumbar UM, Yang BY, Bederson JB. Adenosine-induced transient asystole for management of a basilar artery aneurysm. Case report. J Neurosurg. 1999;91:687-90. 
10. Nussbaum ES, Sebring LA, Ostanny I, Nelson WB. Transient cardiac standstill induced by adenosine in the management of intraoperative aneurysmal rupture: technical case report. Neurosurgery. 2000;47:240-3.

11. Heppner PA, Ellegala DB, Robertson N, Nemergut E, Jaganathan J, Mee E. Basilar tip aneurysm-adenosine induced asystole for the treatment of a basilar tip aneurysm following failure of temporary clipping. Acta Neurochir. 2007;149:517-20.

12. Batjer HH, Kopitnik TA Jr, Giller CA, Samson DS. Surgical management of proximal carotid artery aneurysms. Clin Neurosurg. 1994;41:21-38.

13. Heros RC, Nelson PB, Ojemann RG, Crowell RM, DeBrun G. Large and giant paraclinoid aneurysms: surgical techniques,complications, and results. Neurosurgery. 1983;12:153-63.

14. Fulkerson DH, Horner TG, Payner TD, Leipzig TJ, Scott JA, DeNardo AJ, Redelman K, Goodman JM. Endovascular retrograde suction decompression as an adjunct to surgical treatment of ophthalmic aneurysms: analysis of risks and clinical outcomes. Neurosurgery. 2009;64:107-12.

15. Parkinson RJ, Bendok BR, Getch CC, Yashar P, Shaibani A, Ankenbrandt W, Awad IA, Batjer HH. Retrograde suction decompression of giant paraclinoid aneurysms using a No. 7 French balloon-containing guide catheter. Technical note. J Neurosurg. 2006;105:479-81.
16. Young WL, Lawton MT, Gupta DK, Hashimoto T. Anesthetic management of deep hypothermic circulatory arrest for cerebral aneurysm clipping. Anesthesiology. 2002;96:497-503.

17. Lagerkranser M, Bergstrand G, Gordon E, Irestedt L, Lindquist C, Stange K, Sollevi A. Cerebral blood flow and metabolism during adenosine-induced hypotension in patients undergoing cerebral aneurysm surgery. Acta Anaesthesiol Scand. 1989;33:15-20.

18. Khan SA, McDonagh DL, Adogwa O, Gokhale S, et al. Perioperative cardiac complications and 30-day mortality in patients undergoing intracranial aneurysmal surgery with adenosine-induced flow arrest: a retrospective comparative study. Neurosurgery. 2014;74(3):267-71.

19. Bendok BR, Gupta DK, Rahme RJ, Eddleman CS, et al. Adenosine for temporary flow arrest during intracranial aneurysm surgery: a single-center retrospective review. Neurosurgery. 2011;69(4):815-20.

20. Bebawy JF, Zeeni C, Sharma S, Kim ES, et al. Adenosine-induced flow arrest to facilitate intracranial aneurysm clip ligation does not worsen neurologic outcome. Anesth Analg. 2013;117(5): 1205-10.

21. Luostarinen T, Takala RS, Niemi TT, Katila AJ, et al. Adenosine-induced cardiac arrest during intraoperative cerebral aneurysm rupture. World Neurosurg. 2010;73(2):79-83.

Open Access This chapter is licensed under the terms of the Creative Commons Attribution 4.0 International License (http://creativecommons.org/licenses/by/4.0/), which permits use, sharing, adaptation, distribution and reproduction in any medium or format, as long as you give appropriate credit to the original author(s) and the source, provide a link to the Creative Commons license and indicate if changes were made.

The images or other third party material in this chapter are included in the chapter's Creative Commons license, unless indicated otherwise in a credit line to the material. If material is not included in the chapter's Creative Commons license and your intended use is not permitted by statutory regulation or exceeds the permitted use, you will need to obtain permission directly from the copyright holder. 